\title{
Implementasi Strategi Branding Enterpreneur di TK Khalifah Sewon Yogyakarta
}

\author{
AHMAD MUSHLIH \\ Program Studi Pendidikan Agama Islam \\ Universitas Islam Negeri Sunan Kalijaga Yogyakarta \\ Email: Ahmad_mushlih@yahoo.co.id
}

DOI: https://doi.org/10.29313/ga.v2i2.4292

\begin{abstract}
This research was distributed by a large number of schools which are experiencing a shortage of protégé and even to roll the mat so that it needed a strategy to lure the consumers or the public. Education as an effort to educate the nation and also prepare to meet in a mental maturity protégé, it needs to be fed by skills (soft skills), one of which, namely entrepreneurship. This research uses qualitative research type by using the validity of data triangulation technique. As for the results of studies on the implementation of the branding strategy entrepreneur in Sewon Bantul Yogyakarta Caliph Kindergarten: first Brand Positioning (Excellence-excellence as a criterion with other schools, one example i.e. entrepreneur), second, brand identity (including name, logo, jingle, endorser, design, color, web/social media, characters and slogan and tagline), and the third, brand personality (through the figure of the famous people at the same time the founder of Kindergarten Khalifa i.e. Ippo Santoso).
\end{abstract}

Keywords: Branding Strategy, and Enterpreneur.

\begin{abstract}
Abstrak
Penelitian ini dilatarbelakangi oleh banyaknya sekolah yang mengalami kekurangan anak didik dan bahkan sampai gulung tikar sehingga diperlukan strategi untuk memikat hati para konsumen atau masyarakat. Pendidikan sebagai usaha untuk mencerdaskan bangsa dan juga menyiapkan mental dalam menyongsong kedewasaan anak didik, maka perlu dibekali oleh keterampilan (soft skill), salah satunya yaitu kewirausahaan. Penelitian ini menggunakan jenis penelitian kualitatif dengan menggunakan keabsahan data triangulasi teknik. Adapun hasil penelitian tentang implementasi strategi branding enterpreneur di TK Khalifah Sewon Bantul Yogyakarta yaitu pertama Brand Positioning (keunggulan-keunggulan sebagai pembeda dengan sekolah lain, salah satu contoh yaitu enterpreneur), kedua, brand identity (meliputi nama, logo, jingle,endorser, desain, warna, web/sosial media, karakter serta slogan dan tagline), dan ketiga, brand personality (melalui sosok tokoh terkenal sekaligus pendiri Tk Khalifa yaitu Ippo Santoso).
\end{abstract}

Kata Kunci: Strategi Branding, dan Enterpreneur. 


\section{Pendahuluan}

Lembaga pendidikan anak usia dini di indonesia semakin marak berkembang dari perkotaan sampai pelosok pedesaan. Pendidikan anak usia dini menurut data statistik dari Kementrian Pendidikan dan Kebudayaan pusat data dan statistik pendidikan dan kebudayaan terakhir pada tahun 2017, Daerah Istimewa Yogyakarta memiliki paud/taman kanak-kanan sebanyak, negeri (38 lembaga), swasta $(2,099)$ dan jumlah total taman kanakkanan mencapai 2.138 lembaga taman kanakkanak. Dari jumlah total di indonesia sebanyak, negeri (3.207), swasta (85.174) dan jumlah total di indonesia mencapai 88.381 lembaga taman kanak-kanak. ${ }^{1}$. Banyaknya lembaga pendidikan tentunya semakin tinggi persaingan dalam mencari peserta didik dan menumbuhkan minat orangtua sebagai pengguna lembaga sekolah.

Banyaknya persaingan tentu membuat lembaga sekolah harus terus berinovasi menciptakan hal baru sebagai daya tarik konsumen atau pemakai. Program utama sekolah banyak bermunculan seperti tahfidz, sekolah alam, multikultural, enterpreneur. Di era saat ini banyak bermunculan sekolah-sekolah swasta yang bersaing dengan sekolah-sekolah negeri. Menurut Yayasan Satu Satu Karsa Karya (YSKK) melalui jawa pos menemukan fakta terkait tingkat kepuasan masyarakat terhadap lembaga pendidikan di Surakarta. Dari hasil survei 22 April 2018 di kota/kabupaten di eks Karesidenan Surakarta yang dilakukan, diketahui bahwa masyarakat lebih puas dengan sekolah swasta dibandingkan dengan sekolah negeri dengan persentase swasta $82,9 \%$ dan negeri 75,9 persen. Sehingga banyak sekolah negeri yang re-grouping dan gulung tikar. ${ }^{2}$. Dari kasus tersebut, maka etiap sekolah perlu menerapkan strategi branding untuk meningkatkan kualitas dan daya tarik masyarakat.

\footnotetext{
${ }^{1}$ Pusat Data dan Statistik Pendidikan dan Kebudayaan, "Kementrian Pendidikan Dan Kebudayaan Pusat Data Dan Statistik Pendidikan Dan Kebudayaan" (Jakarta, 2017).

2 JawaPos.com, "Kekurangan Murid, Banyak Sekolah Negeri Gulung Tikar," diakses 13 November 2018, https://www.jawapos.com/pendidikan/02/05/2018/kekuran gan-murid-banyak-sekolah-negeri-gulung-tikar.
}

Strategi branding perlu dilakukan karena ketatnya persaingan antar lembaga sekolah dalam memikat hati masyarakat/orangtua. Sekolah perlu melabeli dirinya dengan sebuah merek (brand) sebagai penunjang dan sarana meningkatkan minat masyarakat terkhusus orangtua. Sebab Merek yang sukses adalah mereka yang menjadi pemimpin (diukur dalam hal pangsa pasar) dikatagorikan produk mereka dipasar yang relevan (domestik/global). ${ }^{3}$ Sehingga untuk menjadi lembaga sekolah yang diminati masyarakat luas, maka perlu dibangun strategi merek yang dapat memikat hati masyarakat. salah satu contoh brad terkenal di indonesia dalam dunia pendidikan yaitu Enterpreneur.

Enterpreneur sebagai salah satu langkah konret untuk menciptakan atau mengubah orientasi cara berpikir masyarakat, maka dari itu, program kegiatan kewirausahaan bagi anak didik sangat penting, sehingga orang dewasa atau orang tua mencoba untuk memberikan bekal keterampilan kewirausahaan sekaligus aplikasi kewirausahaan anak didik. ${ }^{4}$

$$
\text { Pembelajaran kewirausahaan }
$$
merupakan keterampilan aplikatif yang sangat mendukung kesiapan anak didik menghadapi kehidupan masyarakat. ${ }^{5}$ penanaman jiwa kewirausahaan perlu di tanamkan sejak dini agar pikiran anak tidak hanya mengandalkan oranglain ketika dewasa nanti. Mengubah mind set anak ketika dewasa tidak hanya menjadi pegawai, dokter, pilot dan lain sebagainya, akan tetapi yaitu mendidik dan membuat cita-cita anak menjadi enterpreneurship yang mendunia sehingga dapat menciptakan lapangan pekerjaan bagi orang lain. Salah satu sekolah enterpreneur yaitu TK Khalifah Sewon

TK Khalifah Sewon dipilih sebagai Objek penelitian, dikarenakan memiliki brand unggulan yaitu Tauhid dan enterpreneur, hal ini dapat dibuktikan melalui sosial media ataupun website dari TK Khalifah Sewon. Selain itu, prapenelitian

\footnotetext{
${ }^{3}$ Mark Casson, Enterpreneurship (Jakarta: Raja Grafindo, 2012), 324.

4 Bela, Wawancara tentang TK Khalifah Sewon, 5 Desember 2018.

${ }^{5}$ Mohammad Saroni, Mendidik dan Melatih Enterpreneur Muda (Yogyakarta: Ar-Ruzz Media, 2012), 75.
} 
dilakukan dari hasil wawancara dengan bunda Bella, beliau menegaskan bahwasanya sekolah TK Khalifah Sewon adalah TK Berbasis Tauhid dan enterpreneur. Maka dari itu penelitian ini membahas mengenai implementasi strategi branding enterpreneur di TK Khalifah Sewon Bantul Yogyakarta dengan menggunakan unsur brand positioning, brand identity dan brand personality.

\section{Kajian Teori \\ Strategi Branding}

Brand merupakan ide, kata, desain grafis, dan suara/bunyi yang mensimbolkan produk, perusahaan yang memproduksi dan jasa tersebut. 6 Merek menurut Hermawan Kartajaya mengatakan bahwa merek adalah aset menciptakan value bagi pelanggan dengan meningkatkan kepuasan dan menghargai kualitas. ${ }^{7}$ Merek menurut Kotler, Amstrong dan Keller adalah nama, istilah, tanda, simbol, desain atau kombinasi keseluruhannya, yang ditujukan untuk mengidentifikasikan barang atau jasa yang ditawarkan perusahaan sekaligus sebagai diferensiasi produk. ${ }^{8}$

Menurut Kotler yag dikutip oleh Sopia dan Etta mamang Sangaji mengatakan bahwa merek dapat memiliki enam level pengertian yaitu, pertama, Atribut. Merek mengingarkan pada atribut tertentu, misalnya, mercendes memeberikan kesan sebagai mobil yang mahal, dibuat dengan baik, tahan lama dan bergengsi tinggi. Kedua, manfaat, atribut perlu diterjemahkan menjadi manfaat fungsional dan emosional. Ketiga, Nilai, merek juga menyatakan sesuatu tentang produsen, misalnya mercendes berarti kinerja tinggi, keamanan, gengsi dan lain sebagainya. Keempat. Budaya, merek juga mewakili budaya tertentu, misalnya mercendes mewakili budaya jerman. Kelima, kepribadian, merek juga mencerminkan kepribadian tertentu, misalnya, mercendes mencerminkan pemimpin

\footnotetext{
${ }^{6}$ Ike Janita Dewi, Inspirasi Bisnis :Perspektif Baru Dalam Strategi Branding, Bisnis, dan Karir (Yogyakarta: :amara books, 2005), hlm. 14.

Sopiah dan Etta mamang Sangadji, Salesmanship Kepenjualan, 1 ed. (Jakarta: Bumi Aksara, 2016), hlm. 65.

${ }^{8}$ Erna Ferrinadewi, Merek dan Psikologi Konsumen, 1 ed. (Yogyakarta: Graha IImu, 2008), 136.
}

yang masuk akal. Dan keenam, pemakai, merek menunjukkan jenis konsumen yang membeli atau menggunakan produk tersebut. ${ }^{9}$

Penggunaan merek (brand) memiliki berbagai macam tujuan. Pertama, sebagai identitas perusahaan yang membedakannya dengan produk pesaing, sehingga pelanggan mudah mengenali dan melakukan pembelian ulang. Kedua, sebagaii alat promosi yang menonjolkan daya tarik produk (misalnya dengan bentuk desain dan warna-warna yang menarik), ketiga, untuk membina citra, yaitu dengan memberikan keyakinan, jaminan kualitas, serta citra prestise tertentu kepada konsumen. Dan keempat. Untuk mengendalikan dan mendominasi Pasar (dengan membangun merek yang terkenal, bercitra baik dan dilindungi hak eksklusif berdasarkan hak cipta/paten, maka perusahaan dapat meraih dan mempertahankan loyalitas konsumen)..$^{10}$

Branding tidak hanya sebatas logo semata, melainkan bagaimana menggunakan logo untuk memenuhi kebutuhan dalam setiap perubahan. ${ }^{11}$ brand strategy menurut Schultz dan Barnes dapat diartikan sebagai manajemen suatu merek dimana terdapat berbagai kegiatan yang mengatur semua elemen-elemen yang bertujuan untuk membentuk suatu brand. ${ }^{12}$

Pada mulanya unsur pembentuk wujud brand cukup tercakup dalam istilah brand identity; yaitu suatu artikulasi visual dan verbal dari brand. ${ }^{13}$ Menurut Van Gelder yang dikutip

\footnotetext{
9 Sopiah dan Etta mamang Sangadji, Salesmanship kepenjualan, hlm. 65.

${ }_{10}$ Anastasia Diana dan Fandy Tjiptono, prinsip dan Dinamika Pemasaran (Yogyakarta: J \& J Learning, 2000), hlm. 39.

${ }^{11}$ Wilson Chew Jacky Tai, brand manajemen: 13 strategi untuk mengembangkan merek anda (Jakarta: Indeks, 2012), hlm, 2.

${ }^{12}$ Yuri Rahmadhani dan Evawani Elysa Lubis, "STRATEGI BRANDING PORTAL ONLINE WWW.TRIPRIAU.COM DALAM MEMBANGUN BRAND AWARENESS SEBAGAI PORTAL ONLINE PARIWISATA PROVINSI RIAU," Jurnal Online Mahasiswa (JOM) Bidang IImu Sosial Dan IImu Politik 4, no. 1 (24 November 2016): hlm. 1-15.

13 Rudy Farid, "Kajian Strategi Branding Clothing Unkl347," Wimba, Jurnal Komunikasi Visual \& Multimedia. Vol. 8 No. 1 Tahun 2017 (2017): HIm. 59-81, Https:/Webcache.Googleusercontent.Com/Search?Q=Ca che:Abvadqfsvjyj:Https://Jurnalwimba.Com/Index.Php/Wim $\mathrm{ba} /$ Article/Download/123/Pdf_83+\&Cd=1\&Hl=En\&Ct=CInk $\& \mathrm{Gl}=\mathrm{Id}$.
} 
Yuri Rahmadhani mengatakan bahwa strategi branding harus memenuhi tiga elemen yaitu Brand Positioning, Brand Identity dan Brand Personality. ${ }^{14}$

\section{Brand Positioning}

Brand Positioning menurut Koter dan Keller yang dikutip oleh Surachman mengatakan bahwa pemosisian adalah upaya untuk "menancapkan" produk merek kita kedalam benak konsumen di antara produk merek pesaing. ${ }^{15}$ Menurut Ririn dan mastuti dalam bukunya menerangkan bahwa positioning mencakup perencanaan penawaran, dan citra perusahaan agar target pasar mengetahui dan menganggap penting posisi perusahaan di antara pesaing dengan tujuan utama yaitu membedakn persepsi perusahaan berikut produk dan jasanya dari pesaing. ${ }^{16}$

Pada prinsipnya positioning berusaha menempatkan produk dalam benak pelanggan sasaran sedemikian rupa sehingga dipersepsikan secara unik dan unggul dibandingkan produk dan merek pesaing dalam hal atribut dan manfaat produk. ${ }^{17}$ Positioning ini haruslah unik, sehingga merek lembaga/perusahaan didengar dan diperhatikan oleh pasar. Positioning juga harus relevan dengan kebutuhan dan keinginan konsumen. ${ }^{18}$

Menurut Kotler dan Keller, ada tiga langkah dalam menentukan strategi positioning, yaitu Pertama, mengenali keunggulankeunggulan yang dapat ditampilkan dalam hubungan dengan pesaing. Kedua, memilih keunggulan-keunggulan yang paling kuat menonjol. ketiga, menyampaikan keunggulan-

\footnotetext{
14 Yuri Rahmadhani Dan Evawani Elysa Lubis, "Strategi Branding Portal Online Www.Tripriau.Com Dalam Membangun Brand Awareness Sebagai Portal Online Pariwisata Provinsi Riau," hlm. 1-15.

15 Surachman, Dasar-dasar Manajemen Merek, 1 ed. (Malang: Banyumedia Publishing, 2008), hlm. 14.

${ }^{16}$ Ririn Tri Ratnasari dan Mastuti H. Aksa, teori dan Kasis Manajemen Pemasaran Jasa (Bogor: Ghalia, 2011), hlm. 27.

${ }^{17}$ Fandy Tjiptono, Gregorius Chandra, dan Dedi Adriana, Pemasaran Strategik, 1 ed. (Yogyakarta: ANDI, 2008), hlm. 653.

${ }_{18}$ Philip Kotler, Hermawan Kartajaya, dan Iwan Setiawan, Marketing 3.0 (Jakarta: Erlangga, 2010), hlm. 38.
}

keunggulan itu secara efektif pada target pasar. ${ }^{19}$

Sebuah pernyataan pemosisian idealnya merefleksikan keyakinan merek. Untuk itu, menurut Keller, pemosisian harus mengacu pada apa yan disebut mantra merek, yaitu "three to five word phrases thah capture the irrefutable essence or spirit of the band positioninf and bran value. Dengan demikian harus dipastikan bahwa pernyataan pemosisian tidak saling bertentangan dengan jiwa dan hati merek, tetapi sebaliknya harus saling mendukung sehingga pemosisian dapat dikomunikasikan secara tepat, baik kepada pihak internal maupun eksternal. ${ }^{20}$

Menurut Scoot M. Davis ada tiga hal mendasar yang harus dipahami yaitu: pertama, definisi target pasar yang hendakdituju, kedua, definisi ada bisnis mana perusahaan hendak berada atau pada katagori mana industri mana perusahaan berkompetisi, ketiga pernyataan pemosisian terus benar-benar mewakili deferensiasi dan manfaat kunci yang dijanjikan. ${ }^{21}$

\section{Brand Identity}

Identitas sering diartikan sebagai ciri-ciri yang melekat pada suatu objek sehingga membedakannya dengan yang lain. Bagi sebuah merek, memilikiidentitas yang tegas adalah sesuatu yang sangat berharga di tengah ratusan, bahkan ribuan produk yang setiap saat membanjiri pasar. Identitas yang khusuus dan spesifik akan memdahkan mengidentifikasi sebuah merek di antara merek lain. ${ }^{22}$

Aaker dan Joachimsthaler menegaskan bahwa identitas merek juga mensyiarkan berbagai asosiasi yanga kan diciptakan oleh sebuah merek, termasuk janji mereka kepada pelanggan. Untuk itu, identitas harus memiliki jangkauan yang luas dan kaya agar upaya pembangunan merek yang kuat dibenak pelanggan dapat terus dilakukan dalam jangka panjang. Identitas merek juga terkait dengan

\footnotetext{
${ }^{19}$ Ririn Tri Ratnasari dan Mastuti H. Aksa, teori dan Kasis Manajemen Pemasaran Jasa, hlm. 28.

${ }^{20}$ Andi M. Sadat, Brand Belief (Jakarta: Salemba Empat, 2009), hlm. 85.

${ }_{21}$ lbid., hlm.85

22 Ibid., hlm. 48.
} 
etos, tujuan, dan nilai-nilai yang dikomunikasikan kepada pasar sehingga dapat membedakannya dengan merek lain. ${ }^{23}$

\section{Komponen identitas merek}

Beberapa komponenn identitas merek tersebut meliputi, nama, logo, warna, jingle, desain/kemasan, slogan, tagline, endorser erek, situs web. 24

1. Nama

Bagi sebuah produk, nama memiliki beberapa fungsi yaitu, alat pembeda suatu produk dengan pesaingnya, alat promosi dan daya tarik produk, alat untuk membangun citra, pemberi keyakinan, jaminan kualitas dan prestise kepada pelanggan, serta alat pengendali persaingan pasar.

2. Logo

Logo biasanyadigunakan sebagai lambang yang menggambarkan sesuatu.

3. Warna

Warna juga bisa digunakan sebagai lambang pesan dan kesan tertentu, sebagai pengukuh identitas produk agar konsumen lebih mudah dan cepat ingat dengan produk dari perusahaan.

4. Jingle

Pada merek, penggunaan suara yang biasa disebut jingle sering digunakan agar pelanggan dengan mudah mengidentifikasikan sebuah merek. Jingle bagi sebuah merek ibarat lagu kebangsaan proteksi, tujuan penyimpanan dan mempermudahaan sebuah bangsa, siapapun yang mendengarkan akan langsung mengenalinya. Dan memoermudahkonsumsi. Produk harus didesain sedemikian rupa dengan memperhatikan segala sapek terutama kombinasi antara kemudahan penggunaan produk dengan konsep visual yang ada.

5. Desain atau kemasan

Sebuah merek dapat dikenali dari bentuk desain kemasannya. Keller menjelaskan

\footnotetext{
${ }^{23}$ Ibid., hlm. 48.

24 Sopiah dan Etta mamang Sangadji, Salesmanship kepenjualan, hIm. 69-71.
}

bahwa kemasan, baik dari persepektif pelanggan maupun perusahaan, memiliki beberapa tujuan, yaitu alat untuk mengidentifikasi merek, memberikan informasi dan deskripsi produk, tujuan proteksi, tujuan penyimpanan dan memperudah konsumsi. Dengan demikian, kemasan dapat berfungsi sebagai alat komunikasi yang efektif kepada pelanggan sehingga harus didesain sedemikian rupa dengan memperhatikan berbagai aspek. ${ }^{25}$

6. Slogan dan tagline

Sebuah slogan dan tagline memiliki tujuan yng berbeda. Sebuah tagline adalah slogan, namun slogan belum tentu tagline. Tagline biasanya dirumuskan secara mendalam untuk mengkomunikasikan pemosisian merek. Untuk itu penempatan tagline biasanya berdampingan dengan logo perusahaan, sedangkan slogan sering digunakan untuk iklan yang bertujuan membangkitkan ingatan atau kesadaran pelanggan terhadap merek secara cepat.

7. Endorser merek

Seseorang yang dijadikan ikon merek sebuah produk disebut endorser. Para endorser biasanya dipilih dari kalangan selebriti yang terkenal di masyarakat luas. Tujuan hal ini adalah agarefek ketokohan juga akan menular pada merek yang diiklankan.

8. Karakter

Mempermudah proses komunikasi agar merek mudah dikenal, beberapa perusahaan mengaitkan dengan sebuah karakter tertentu seperti kartun hewan, atau kombinasi unik lainnya.

9. Situs web dan url

Uniform resource Locators (URL) atau nama domain di dunia maya sangat penting untuk mendeteksi web sebuah merek. Saat ini keberadaan alamat situs web seolah menjadi hal yang wajib, tidak hanya untuk memudahkan pencarian informasimengenai manfaaat yang ditawarkan oleh merek, melainkan juga bisa digunakan sebagai media komunikasi intensif kepada

\footnotetext{
${ }^{25}$ Andi M. Sadat, Brand Belief, hlm. 67.
} 
pelanggan dan menjaga citra di mata kolega bisnis, singkatnya URL enjadi bagian dari identitas merek yang sangat penting.

\section{Brand Personality}

Pengertian brand personality menurut Gelder adalah suatu cara yang bertujuan untuk menambah daya tarik merek dari luar dimata konsumen. Kemudian menurut Crainer dan Dearlove brand personality adalah merek yang didapat dari suatu karakter melalui komunikasi tentang merek dan pengalaman dari merek serta dari orang yang memperkenalkan merek. Sedangkan menurut Keller, karakteristik manusia atau ciri-ciri yang dapat diatributkan kepada suatu merek. Jadi brand personality adalah suatu cara yang bertujuan untuk menambah daya tarik dari brand dengan memberi karakteristik pada brand tadi, yang bisa didapat melalui komunikasi, pengalaman serta dari orang yang memperkenalkan brand itu sendiri. ${ }^{26}$

Brand value membentuk brand personality, brand personality lebih cepat berubah dibanding brand positioning, karena brand personality mencerminkan gejolak perubahan selera kosumen. Contohnya adalah komik cerita wayang saat ini tidak lagi sesuai dengan selera para remaja Indonesia, karena seleranya lebih banyak dipengaruhi oleh komikkomik gaya Sakura Taisen, seperti Crayon Shin chan, dan lain sebagainya. ${ }^{27}$

Aaker mengembangkan lima dimensi brand personality yang terdiri dari sincerity, excitement, cometence, sophistication dan ruggedness. Dimensi ketulusan (sincerity) merek terdiri dari beberapa item yaitu rendah hati, jujur, sederhana, dan gembira. Dimensi excitement terdiri dari berani, semangat imaginative dan modern. Dimensi competance terdiri dari glamor dan pesona. Dimensi ruggedness terdiri dari

\footnotetext{
${ }^{26}$ Yuri Rahmadhani Dan Evawani Elysa Lubis, "Strategi Branding Portal Online Www.Tripriau.Com Dalam Membangun Brand Awareness Sebagai Portal Online Pariwisata Provinsi Riau," hlm. 1-15.

${ }^{27}$ Freddy Rangkuti, The Power Of Brands, 4 ed. (Jakarta: Gramedia, 2009), hlm. 7.
}

gagah dan kuat. ${ }^{28}$ Merek yang dipilih merupakan cara untuk mengekspresikan diri dan hubungan antar merek, dan konsumen semacam ini dapat terbentuk berdasarkan pada hubungan antar indvidu atau kelompok.

Kepribadian merek sesungguhnya merupakan respon emosional konsumen terhadap merek yang membedakannya dengan merek pesaingnya. Bagi pemasar, hal yang perlu diingat dalam merancang strategi branding adalah kecenderungan konsumen untuk secara konsisten mengkonsumsi merek yang sama dalam jangka waktu lama agar dapat menggambarkan kepribadiannya. Misalnya merek sabun Lux yang selalu menggunakan bintang ternama untuk mengkomunikasikan kepribadian lux sebagai sabun kecantikan yang mewah). ${ }^{29}$

Kepribadian merek berhubungan dengan ikatan emosi merek tersebut dengan manfaat merek itu sendiri sebagai dasar untuk diferensiasi merek dan hubungan pelanggan. Kepribadian merek akan melibatkan dimensi yang unik untuk sebuah merek. ${ }^{30}$

\section{Enterpreneur}

Enterpreneurship berasal dari bahasa inggris, dalam bahasa indonesia berarti kewirausahaan. Dalam bahasa jerman disebut unternehmer dan ondernemer dalam bahasa belanda. Kata enterpreneur berasal dari bahasa prancis yaitu entreprende yang berarti petualang, pengambil resiko, kontraktor, pengusaha (orang yang mengusahakan suatu pekerjaan tertentu), dan pencipta yang menjuall hasil ciptaannya. ${ }^{31}$. Menurut Peter F. Druck yang dikutip oleh muhammad anwar mengatakan bahwa kewrausahaan erupakan kemampuan dalam menciptakan sesuatu yang baru dan beda $^{32}$. Menurut Scarborough, Zimmerer dan Wilson yang dikutip oleh Franky Slamet adalah

${ }^{28}$ Erna Ferrinadewi, Merek dan Psikologi Konsumen, hlm. 156.

29 Ibid., hlm. 158.

${ }^{30}$ Etta mamang Sangadji dan Sopiah, Perilaku Konsumen (Yogyakarta: ANDI, 2013), hlm. 331.

Muhammad Anwar, Pengantar Kewirausahaan Teori Dan Aplikasi, 1 Ed. (Jakarta: Prenada, 2014), 2.

32 ibid.,hlm. 2. 
seseorang yang menciptakan bisnis baru dan mengamil resiko dan ketidakpastian demi mencapai keuntungan dan pertumbuhan yang signifikan dengan cara mengidentifikasi peluang dan menggabungkan sumber-sumber daya yang diperlukan sehingga sumber daya tersebut dapat dikapitalisasikan ${ }^{33}$. Kewirausahaan atau enterpreneurship adalah suatu intangibleculture, suatu kemampuan non fisical yang mampu menggerakkan sosok fisikal. Kewirausahaan menggkombinasikan empat faktor produksi yaitu land, labour, capital dan skill. ${ }^{34}$

David Mc Clelland menyatakan ada 9 karakteristik utama yang terdapat dalam diri seorang wirausaha sebagai berikut: Pertama, Dorongan berprestasi: Semua wirausahawan yang berhasil memilki keinginan besar untuk mencapai suatu prestasi. Kedua, Bekerja keras, ketiga, Memperhatikan kualitas. keempat, Sangat bertanggung jawab. Kelima, Berorientasi pada imbalan, keenam, Optimis. Ketujuh, Berorientasi pada hasil karya yang baik (excelence oriented). kedelapan, Mampu mengorganisasikan. Sembilan, Berorientasi pada uang ${ }^{35}$

\section{Metode Penelitian}

Penelitian ini menggunakan pendekatan kualitatif, dengan teknik pengumpulan data melalui observasi, wawancara dan dokumentasi. Adapun lokasi penelitiannya yaitu di TK Khalifah Sewon, Bantul, Yogyakarta tepatnya di jl. Imogiri Barat No.33, Ngoto, Bangunharjo, Sewon, Bantul, Daerah Istimewa Yogyakarta 55188. Penelitian ini melibatkan pengelola TK Khalifah Sewon dan guru kelas. Sebagai bentuk bentuk pengecekan keabsahan data, peneliti menggunakan triangulasi teknik.

\footnotetext{
${ }^{33}$ Franky Slamet, Herru Karunia Tunjungsari, dan Mei le, Dasar-dasar Kewirausahaan teori dan Praktik, 1 ed. (Jakarta Barat: Indeks, 2014), 3.

${ }_{34}$ Sonny Sumarni, Kewirausahaan, 2 Ed. (Yogyakarta: Graha Ilmu, 2013), hlm. 3.

35 Mudjiarto Aliars Wahid, Membangun Karakter Dan Kepribadian Kewirausahaan, (Graha Ilmu: Yogyakarta, 2016), hlm. 3.
}

\section{Hasil Penelitian}

TK Khalifah Sewon telah berdiri sejak tahun 2013. Terhitung sudah lima tahun berjalan sampai tahun 2018. Selama perjalanan ini tentunya memiliki berbagai strategi dalam memasarkan atau mempublikasikan pada khalayak ramai, dan salah satunya yaitu penggunaan strategi branding. Strategi ini merupakan sebuah manajemen yang berkaitan dengan merek, dimana terdapat berbagai kegiatan yang mengatur semua elemen-elemen yang bertujuan untuk membentuk suatu merek dari sebuah lembaga.

Adapun implementasi strategi branding enterpreneur di TK Khalifah Sewon sebagai berikut:

\section{Brand Positioning}

Brand positioning sebagai brand/merek berada pada posisi dari berbagai lembaga atau perusahaan untuk mendapatkan hati para konsumen. Brand positioning dalam tujuannya mengedepandakan suatu pembeda baik layanan maupun produk kepada khalayak ramai (masyarakat) sehingga menjadi nilai tersendiri dari sebuah lembaga/perusahaan.

Brand positioning sebagai bagian dari strategi branding, di TK Khalifah Sewon memiliki berbagai keunggulan sebagai pembeda unttuk menarik konsumen/pemakai jasa, yaitu:

a. Sebagai sekolah taman pendidikan kanak-kanak berbasis enterpreneur dan tauhid.

b. Memiliki core value berupa jujur, sungguh-sungguh, santun, ceria, dan mandiri yang terintegrasi dalam aktivitas pembelajaran maupun diluar pembelajaran.

c. Menerapkan dan membiasakan penggunaan tujuh kata ajaib khalifah yaitu maaf, tolong, bolehkah, silahkan, terimakasih dan alhamdulillah, semuanya terintegrasi dalam aktifitas disekolahan.

d. Small Class, mengawasi tumbuh kembang lebih intensif

e. Outing class setiap bulan 
f. Sekolah dibangun dan di desain seperti suasana rumah dan menjadi rumah kedua bagi anak didik.

\section{Brand identity}

Identitas merek merupakan sebuah ciriciri yang melekat pada perusahaan atau lembaga sebagai pembeda dari yang lain. Identitas merek peru dibangun untuk mengenali sebuah produk atau hasil (output) dari sebuah kinerja suatu perusahaan atau lembaga. Oleh karena itu, identitas merek penting adanya dalam sebuah strategi branding.

Di Tk khalifah sewon tentunya sebagai lembaga pendidikan memiliki sebuah identitas diri sebagai salah satu strategi branding menarik para konsumen (masyarakat). adapun brand identity atau identitas merek di TK Khalifah Sewon yaitu:

a. Nama

Nama TK Khalifah diambil dari AlQur'an, Khalifah diisyaratkan sebagai pemimpin di muka bumi dan memiliki peran untuk menjaga dan mengembangkan diri serta saling menyayangi antar ciptaan Allah SWT. Selain itu, khalifah memiliki peran dan tugas untuk beribadah kepada allah SWT. Diharapkan dengan nama TK Khalifah dapat menjadi motivasi dan pandangan dalam menstimulasi anak untuk memiliki jiwa pengusaha dan tetap ingat kepada Allah SWT.

b. Logo

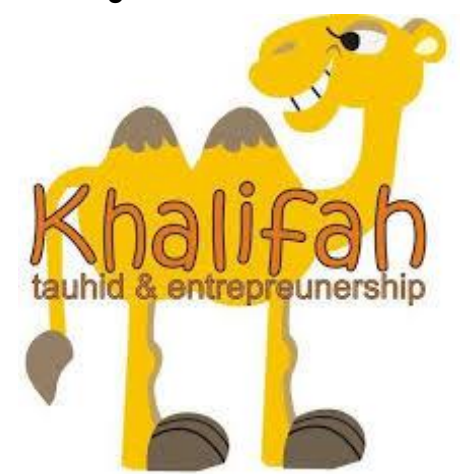

Logo menjadi sebuah ciri khas yang menjadi pembeda dari lembaga satu ke lembaga lainnya. Hasil wawancara dengan bunda Bela, pemilihan unta menjadi simbol kegigihan dan kekuatan perjuangan dalam menjalani proses kehidupan pada zaman Rasulullah, selain itu unta tersenyum dikarenakan, senyum adalah sebagian dari ibadah.

c. Warna

TK Khalifah identik dengan warna orange, begitu juga di Tk Khalifah sewon Bantul, Warna orang emnjadi sebuah identitas bagi Tk Khalifah dimanamun berada. Hal ini menjadi strategi branding untuk menuju visi TK Khalifah, yaitu Menjadi salah satu PG dan TK Islam favorit di Indonesia. Sehingga warna orange dipilih sebagai warna identitas TK Khalifah.

d. Jingle

Penggunaan suara atau lagu sebagai bagian brand identity (identitas merek) menjadi penting adanya sebagai pengingat ketika seseorang/masyarakat mendengarnya langsung mengetahui mars atau lagu milik lembaga tertentu. Tk Khalifah Sewon mengikuti Mars Tk Khalifah pada umumnya, yaitu mars yang berjudul "aku anak khalifah".

\section{Aku Anak Khalifah}

Aku anak khalifah, Jujur santun ceria $2 x$

Susngguh-sungguh, berusaha, siap mandiri bahagia $2 x$

Aku anak khalifah, ingin jadi pengusaha $2 x$

Saling bantu pada sesama, sholat dhuha selamanya $3 x$

e. Desain atau kemasan

Desain atau kemasan menjadi bagian penting sebagai identitas merek sebuah produk dari lembaga yang membedakan dengan yang lain. Pembuatan desain/kemasan disesuaikan dengan pangsa pasar 


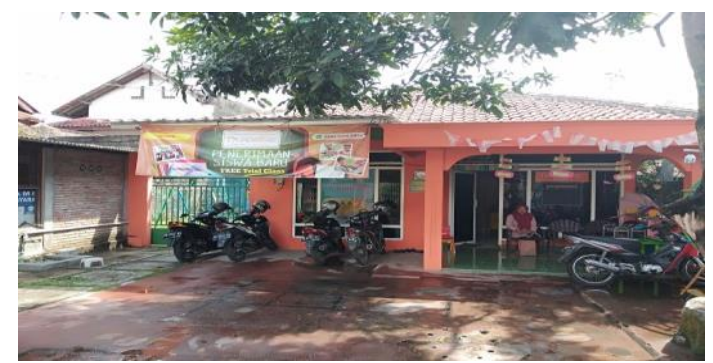

atau target serta tujuan dari desain yang dipasarkan.

Tk Khalifah Sewon memiliki desain atau kemasan lembaga pendidikan anak usia dini (taman kanak-kanak) menyerupai rumah anak didik itu sendiri. Bunda bella menjelaskan (saat wawancara) bahwa Tk Khalifah Sewon di desain seperti rumah kedua bagi anak, agar anak nyaman seperti dirumahnya sendiri. Suasananya juga dibangun senyaman mungkin dan disesuaikan dengan karakteriistik anak. ruang belajar di konsep seperti belajar di rumah.

f. Slogan dan tagline

Slogan sebagai bahasa pemasaran sebagai bentuk membangkitkan sebuah ingatak terhadap merek lembaga/ perusahaan. TK Khalifah Sewon sendiri memiliki slogan yaitu "Berkah berlimpah". Sedangkan tagline sebagai sarana pemosisian merek tentunya sama dengan TK Khalifah yang lain yaitu "Tauhid dan Enterpreneur"

g. Endorser

Endorser adalah seseorang yang dijadikan ikon merek sebuah produk. TK Khalifah Sewon melibatkan tokoh pendiri dari Tk Khalifah yang sekaligus menjadi Enterpreneur muslim, trainer enterpreneur dan motivator yaitu Ippo Santoso sebagai endorser dalam bagaian dari identitas dari sebuah brand.

h. Karakter

Karakter sebagai pelekat dari sebuah merek dan menjadi daya tarik masyarakat dan orangtua. TK Khalifah Sewon melekatkan sebuah karakter binatang Unta sebagai gambaran dari TK Khalifah Sewon.

i. Situs Web atau URL

Di era digital, dalam memasarkan sebuah produk akan lebih efektif selain brosur yaitu menggunakan jaringan internet, seperti website, sosial media dan lain sebagainya. TK Khalifah Sewon dalam mengenalkan brand nya menggunakan Website dan sosial media (Facebook, Instagram).

\section{Brand Personality}

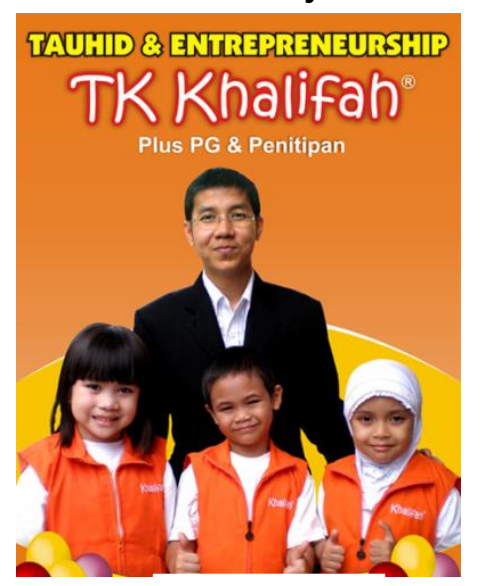

brand

personality

bertujuan

untuk

menambah

daya tarik

dari merek

dengan

memberi

karakteristik

pada merek

tersebut, dan

Gambar 1.3

bisa didapat

dengan melalui

komunikasi,

pengalaman serta dari orang yang memperkenalkan brand itu sendiri.

Ippo Santoso sebagai pendiri TK Khalifah, sekaligus Enterpreneurship muslim, motivator, penulis buku dan lain sebagainya. Menjadi daya tarik bagi masyarakat/orangtuanya mensekolahkan anaknya di TK Khalifah. Bunda Bela (wawancara) mengatakan bahwa sosok Ippo Santoso menjadi bagian salah satu alasan mensekolahkan anaknya di Tk Khalifah agar dapat menjadi seorang pengusaha.

\section{Kesimpulan}

Berdasarkan paparan data di atas, kajian mengenai implementasi strategi branding dapat disimpulkan sebagai berikut: 


\section{Brand positioning}

TK Khalifah Sewon memiliki pembeda dari sekolah lain yaitu berbasis enterpreneur, Memiliki core value, membiasakan tujuh kalimat ajaib, smaal class, outing class, dan sekolah dibangun dan di desain seperti rumah anak didik dan menjadi rumah kedua bagi bagi anak didik.

2. Brand identity Identitas merek yang digunakan oleh TK Khalifah Sewon yaito, Nama, Logo, warna, jingle, desain atau kemasan, slogan dan tagline, endorser, karakter, web/URL

3. Brand personality

Brand personality dibangun melalui sosok tokoh terkenal sekaligus pendiri Tk Khalifa yaitu Ippo Santoso.

\section{Daftar Pustaka}

Anastasia Diana, dan Fandy Tjiptono. 2000. prinsip dan Dinamika Pemasaran. Yogyakarta: J \& J Learning.

Andi M. Sadat. 2009. Brand Belief. Jakarta: Salemba Empat.

Bella. Wawancara tentang TK Khalifah Sewon, 5 Desember 2018.

Erna Ferrinadewi. 2008.Merek dan Psikologi Konsumen. 1 ed. Yogyakarta: Graha IImu.

Etta mamang Sangadji, dan Sopiah. 2013. Perilaku Konsumen. Yogyakarta: ANDI.

Fandy Tjiptono, Gregorius Chandra, dan Dedi Adriana. 2008. Pemasaran Strategik. 1 ed. Yogyakarta: ANDI.

Franky Slamet, Herru Karunia Tunjungsari, dan Mei le. 2014. Dasar-dasar Kewirausahaan teori dan Praktik. 1 ed. Jakarta Barat: Indeks.

Freddy Rangkuti. 2009. The Power Of Brands. 4 ed. Jakarta: Gramedia.

Ike Janita Dewi. 2005. inspirasi bisnis :perspektif baru dalam strategi branding, bisnis, dan karir. Yogyakarta: :amara books.

Jacky Tai, Wilson Chew. 2012. brand manajemen: 13 strategi untuk mengembangkan merek anda. Jakarta: Indeks.
JawaPos.com. "Kekurangan Murid, Banyak Sekolah Negeri Gulung Tikar." Diakses $13 \quad$ November 2018. https://www.jawapos.com/pendidikan/02 105/2018/kekurangan-murid-banyaksekolah-negeri-gulung-tikar.

Mark Casson. 2012. Enterpreneurship. Jakarta: Raja Grafindo.

Mohammad Saroni.2012. Mendidik dan Melatih Enterpreneur Muda. Yogyakarta: ArRuzz Media.

Mudjiarto Aliars Wahid. 2016. Membangun Karakter dan Kepribadian Kewirausahaan,. Graha IImu: Yogyakarta.

Muhammad Anwar. 2014. Pengantar Kewirausahaan teori dan aplikasi. 1 ed. Jakarta: Prenada.

Philip Kotler, Hermawan Kartajaya, dan Iwan Setiawan. 2010. Marketing 3.0. Jakarta: Erlangga.

Pusat Data dan Statistik Pendidikan dan Kebudayaan. "Kementrian Pendidikan Dan Kebudayaan Pusat Data Dan Statistik Pendidikan Dan Kebudayaan." Jakarta, 2017.

Ririn Tri Ratnasari, dan Mastuti H. Aksa. 2011. teori dan Kasis Manajemen Pemasaran Jasa. Bogor: Ghalia.

Rudy Farid. "KAJIAN STRATEGI BRANDING CLOTHING UNKL347." Wimba, Jurnal Komunikasi Visual \& Multimedia. Vol. 8 No. 1 Tahun 2017 (2017). https://webcache.googleusercontent.co $\mathrm{m} / \mathrm{search}$ ? $\mathrm{q}=$ cache:ABVaDQFsVJYJ:htt ps://jurnalwimba.com/index.php/wimba/a rticle/download/123/pdf_83+\&cd=1\&hl=e n\&ct=clnk\&gl=id.

Sonny Sumarni. 2013. Kewirausahaan. 2 ed. Yogyakarta: Graha IImu.

Sopiah, dan Etta mamang Sangadji. 2016. Salesmanship kepenjualan. 1 ed. Jakarta: Bumi Aksara.

Surachman. 2008. Dasar-dasar Manajemen Merek. 1 ed. Malang: Banyumedia Publishing.

Yuri Rahmadhani, dan Evawani Elysa Lubis. "STRATEGI BRANDING PORTAL 
ONLINE WWW.TRIPRIAU.COM

DALAM MEMBANGUN BRAND

AWARENESS SEBAGAI PORTAL

ONLINE PARIWISATA PROVINSI
RIAU." Jurnal Online Mahasiswa (JOM)

Bidang IImu Sosial Dan IImu Politik 4, no. 1 (24 November 2016): 1-15. 